\title{
Nutritional Status and Associated Factors Among Pastoralist Children Aged 6-23 Months in Benna Tsemay Woreda, South Omo Zone, Southern Ethiopia
}

\author{
Anteneh Tadesse ${ }^{1,}$, Dejene Hailu ${ }^{2}$, Tafese Bosha ${ }^{3}$ \\ ${ }^{1}$ Southern Agricultural Research Institute, Jinka Agricultural Research Center, Jinka, Ethiopia \\ ${ }^{2}$ Collage of Medicine and Health Science, Hawassa University, Hawassa, Ethiopia \\ ${ }^{3}$ School of Nutrition, Food Science and Technology, Hawassa University, Hawassa, Ethiopia
}

Email address:

antufspt@yahoo.com (A. Tadesse), dejenkassa@yahoo.com (D. Hailu), tafese.bosha@gmail.com (T. Bosha)

${ }^{*}$ Corresponding author

\section{To cite this article:}

Anteneh Tadesse, Dejene Hailu, Tafese Bosha. Nutritional Status and Associated Factors Among Pastoralist Children Aged 6-23 Months in Benna Tsemay Woreda, South Omo Zone, Southern Ethiopia. International Journal of Nutrition and Food Sciences.

Vol. 7, No. 1, 2018, pp. 11-23. doi: 10.11648/j.ijnfs.20180701.13

Received: May 25, 2017; Accepted: June 20, 2017; Published: December 20, 2017

\begin{abstract}
Nutritional status of children is an important outcome measure of their health status. However, nutritional status and associated factors of pastoralist children were not well documented in Benna Tsemay Woreda, South Omo Zone, Southern Ethiopia. Therefore, this study was designed to assess nutritional status and associated factors among pastoralist children aged 6-23 months in Benna Tsemay Woreda, South Omo Zone, Southern Ethiopia. A community-based cross sectional study was conducted among 645 pastoralist children aged 6-23 months from February-March 2016. A stratified random sampling technique was used to select kebeles (smallest administrative unit) and children. Out of thirty-two kebeles, six were randomly selected. Data were collected using a structured questionnaire, 24 hour food recall and anthropometric measurements. Quantitative data were collected and analyzed using SPSS for windows version 20.0. Anthropometric indices were computed using WHO Anthro 2011 software (version 3.2.2). Bivariate and multivariable logistic regression analyses were conducted. Crude odds ratio (COR) and adjusted odds ratio (AOR) with 95\% confidence interval (CI) were reported. Prevalence of stunting and underweight were higher in fewer than two children in Benna Tsemay compared to the national average. This study showed, being older child (12-23 months) ( $\mathrm{AOR}=3.29,95 \% \mathrm{CI}, 2.03-5.32)$, being from agro-pastoralist $(\mathrm{AOR}=0.46,95 \% \mathrm{CI}, 0.24-0.88)$, middle wealth quantile household $(\mathrm{AOR}=0.40,95 \% \mathrm{CI}, 0.20-0.77$ ), use of treated water ( $\mathrm{AOR}=0.60,95 \% \mathrm{CI}, 0.37-0.96)$, being second birth order ( $\mathrm{AOR}=2.17,95 \% \mathrm{CI}, 1.11-4.24)$, being female child ( $\mathrm{AOR}=0.55,95 \% \mathrm{CI}, 0.37-0.82)$ and good child feeding practice of mothers ( $\mathrm{AOR}=0.47,95 \% \mathrm{CI}, 0.28-0.78)$ were significantly associated with stunting of pastoralist children in Benna Tsemay Woreda $(\mathrm{p}<0.05)$. Having large family size ( $\geq 6$ individuals) ( $\mathrm{AOR}=30.93,95 \% \mathrm{CI}, 4.91-194.7$ ), polygamous marriage $(\mathrm{AOR}=2.46,95 \% \mathrm{CI}, 1.07-5.61)$, being from agro-pastoralist $(\mathrm{AOR}=0.19,95 \% \mathrm{CI}, 0.05-0.66)$ and farming as maternal occupation $(A O R=3.00,95 \% \mathrm{CI}, 1.36-6.62)$ were significantly affected with thinness of children $(\mathrm{p}<0.05)$. Being from pastoralist ( $\mathrm{AOR}=3.18,95 \% \mathrm{CI}, 1.74-5.81)$ and being female child $(\mathrm{AOR}=0.35,95 \% \mathrm{CI}, 0.14-0.89)$ were significantly predicted underweight in children $(\mathrm{p}<0.05)$. In conclusion, high numbers of pastoralist children are suffering from chronic malnutrition with low dietary diversity score (DDS). Large numbers of mothers have poor infant and young child feeding (IYCF) practices. Being from pastoralist and poor family, elder and male child, and poor IYCF practices, polygamous marriage, and poor health service are factors for child under nutrition. Therefore, the authors recommend interventions targeting on community-based nutrition education on IYCF, dietary diversity, cultural food taboos, and family planning in Benna Tsemay pastoralist community.
\end{abstract}

Keywords: Nutritional Status, Associated Factors, Pastoralist Area 


\section{Introduction}

Nutritional status of children is an important outcome measure of their health status [9]. Infant and young child feeding practices directly affect the nutritional status of children under two years, impacting on child survival [7].

Nationally, $40 \%$ of children under age five were stunted, $9 \%$ wasted and $25 \%$ underweight. The prevalence of stunting in children below five years in SNNPR averages about $44 \%$, which is higher than the national average. The prevalence of wasting is higher among the pastoralist communities [9]. Overall, 9\% of Ethiopian children are wasted, and $3 \%$ are severely wasted. The prevalence of stunting, wasting and underweight of under two year children in Ethiopia were $23.2 \%, 16.6 \%$ and $12.5 \%$ respectively [10].

The prevalence of malnutrition in Ethiopia is relatively well documented, but not specific to the regions, localities and residence so far. It is also varies among agrarian, mixed farming, agro-pastoralists and pastoralist communities. Data regarding the conditions of pastoralist areas is limited. Study conduct in other districts is not addressing the main associated factors of malnutrition in pastoralis tareas [10]. This study aimed to assess nutritional status and associated factors in children aged 6-23 months in Benna Tsemay Woreda, South Omo Zone, Southern Ethiopia.

\section{Materials and Methods}

\subsection{Description of the Study Area}

The study was conducted in Benna Tsemay Woreda, South Omo Zone of Southern Ethiopia. This area is located $739 \mathrm{~km}$ South of Addis Ababa, the capital of Ethiopia and $551 \mathrm{~km}$ South of Hawassa, the capital of SNNPR. There are 32 Kebles in the woreda. According to Central Statistical Agency Population projection of 2015, the total population of Benna Tsemay woreda is 62,414 out of which 31,638 are males and 30,776 are females. The woreda is named after the two dominant local ethnic groups namely, Benna and Tsemay, which constitute $48.6 \%$ and $36.1 \%$ of the population, respectively [8]. The remaining $15.3 \%$ of the population is composed of people of other ethnic groups. There are 3 health centers, 27 health posts and 10 medium private clinics provide basic health care for the community at Benna Tsemay Woreda. Most of the kebeles are served by health posts, which focus on preventive aspects and are equipped with junior health extension workers. The livelihood of the local people in the district is based on mixed farming but pastoralism predominates over crop production.

\subsection{Study Design and Period}

Community-based cross sectional study was used to assess child feeding practices, nutritional status and associated factors among pastoralist children aged 6-23 months in the study area. The study employed both qualitative and quantitative methods to collected data from February-March 2016.

\subsection{Sample Size Determination}

Sample size estimation was carried out for each specific objective using double population proportion formula and the largest sample size of the specific objectives was taken as the total sample size of this study. Accordingly, the following assumptions were used to determine the largest sample size of the objectives: $95 \%$ confidence interval $(\mathrm{CI})$, power of test $=80 \%$, ratio of exposed to unexposed $1: 1$, non-response rate $=10 \%$, (odds ratio=1.86, design effect $=1.5$ and $42 \%$ proportion of children's whose mothers are not educated were stunted [10]. Finally an Epi-Info software version 7.0.8.3, Statical application with the above assumptions provided a sample size of 646 households and this was the total sample size of the study.

\subsection{Sampling Technique}

A stratified random sampling technique was used to select kebeles and pastoralist children. There are 32 kebeles in Benna Tsemay woreda. The kebeles was stratified based on the pattern of livelihood system of the communities into pastoralist, agro pastoralist and farmers. Simple random sampling was used to select two kebeles from each stratum and a total of six kebeles were selected out of 32 kebeles.

A sampling frame was prepared by listing all households that have 6-23 months old children in the selected kebeles. One's households with under 6-23 month children were identified, the total calculated sample size was distributed for each kebeles by using proportional to size allocation. After that, simple random sampling was used to select the required number of children from the respective kebeles. Finally, the youngest child from the household in the restricted age group was taken as an index child regardless of sex discrimination. Only one child was selected using lottery method when more than one child is found in a given household.

\subsection{Data Collection}

A pretested and structured questionnaire was used to assess socio-demographic and economic characteristics, maternal and child's characteristics, water supply, sanitation and personal hygiene conditions, health service availability and health seeking behavior and mother's knowledge and practice towards child feeding.

Mother's knowledge and practice towards child feeding in children 6-23 months of age was assessed using structured questionnaire according to the current recommendation of World Health Organization [35]. Early initiation of breast feeding, exclusive breast feeding, time of introduction of solid, semi-solid or soft foods, minimum dietary diversity and minimum meal frequency for non-breast fed children was determined.

\section{Anthropometric measurements}

Recumbent length and weight measurements with data on 
age and sex were collected to assess the nutritional status of children aged 6-23 months. Age of the child was calculated both from the child's date of birth and date of interview, since the year of birth is frequently reported in correctly. Immunization card was also used as an official document to estimate age of the child. In events where birth dates are not recorded or known with certainty, the mother/caregiver were probed for the approximate date of birth based on a local events calendar like harvesting time. If the age of a neighbour's child is known, the mother was asked whether their child was born before or after the "reference" to estimate their child age. The age was calculated using precise day by subtracting the date of birth from the date of data collection [36]. Height cut-offs $(<85 \mathrm{~cm})$ was also used to estimate child age.

The weight of the children age 6-23 was measured to the nearest $0.1 \mathrm{~kg}$ on a battery powered digital scale (Seca 770 , Hanover Germany) and length of the child aged 6-23 months was measured in a recumbent position to the nearest $0.1 \mathrm{~cm}$ using a length board with a sliding head bar following standard anthropometric techniques. Children who were unable to stand on the scale were weighed with the mother or caregiver, then the mother/caregiver was weighed alone, and the difference was used to obtain the net weight of the child. Each study subjects were remove their shoes, jackets and wearing light cloth during weight and height measurements.

The instrument was checked and adjusted to zero for each measurement. A form in the structured questionnaire was used to record information on anthropometric measurements. Duplicate measurements of weight and height were taken at the same day from each study subject using calibrated equipment's and standardized techniques. To avoid variability among the data collectors, all the anthropometric measurements were taken by the researcher (principal investigator). Anthropometric data were collected to calculate three indices of nutritional status: length-for-age, weight-for-length, and weight-for-age. All the anthropometric variables that were used in the evaluation of nutritional status were included.

\subsection{Data Quality Control}

The questionnaire was originally prepared in English and translated to local language "Bennga" and "Tsemayga" and back translated to English by two people for consistency and to avoid information bias. To avoid information bias data collectors were also selected from both Benna and Tsemay ethnic groups. Five percent $(5 \%)$ of the questionnaire was pretested in local language to make sure that the questions would clear and could be understood by respondents before formal data collection. The pre-test was done out of the study kebeles.

A face-to-face interview was used to collect data using structured questionnaire. Diplomated nurses who are fluent in the local language "Bennga" and "Tsemayga" was used to administer questionnaires. Training was provided for data collectors.

Standardisation test was done for enumerators, weight, height and MUAC. Practical training for two days before the field test was given to each team member in order to ensure the standardization of methods. Six enumerators were taken the measurements of at least 10 children 6-23 months twice, with an interval of time between the $1^{\text {st }}$ and the $2^{\text {nd }}$ measure. Measurements of length and weight were taken in duplicate on each child. The weight scale was calibrated to zero level with no object on it before weighing every child. Continuous check-up of scales was carried out for their reliability. Data validity and reliability was maintained through close supervision of data collectors by the principal investigator. The principal investigator supervised and reviews every questionnaire for completeness and logical consistency and corrections was made on the spot.

\subsection{Data Analysis}

First, the data was checked for completeness, coded and entered into a computer. SPSS for windows version 20.0 (SPSS Inc) was used for statistical data analysis. Anthropometric indices were calculated using WHO Anthro 2011 software (version 3.2.2). Normality of continuous variables was checked using histograms and Q-Q plots. Descriptive statistics such as frequency, percentages and mean and standard deviation was used to present the study results.

Bivariate and multivariable logistic regression analyses were conducted to see the association of each independent variable on nutritional status of the pastoralist children. Both crude odds ratio (COR) and adjusted odds ratio (AOR) with $95 \%$ confidence interval was reported to indicate the strength of association between nutritional status of children and predictor variables. Significant variables with a p-value less than 0.25 observed in the bivariate analysis were subsequently included into the multivariable analysis to control potential confounders. In the multivariable logistic regression analysis, variables with a $\mathrm{p}$-value of $<0.05$ were considered as statistically significant.

Hosmer - Lemeshow test was performed for model fitness. P-value $>0.05$ was considered a good fit. Linear regression analysis techniques were used for colinearity diagnostics. Multicollinerity effect for potential factors was checked by Variation Inflation Factor (VIF) value greater than 10 and tolerance value less than 0.1 . No colinearity was found. Statistical graphs and tables were used to represent the study results. Household wealth index was estimated from asset and utility services ownership using principal component analysis (PCA) according to the Ethiopian Demographic and Health Survey (EDHS) wealth index [10]. The wealth index was then divided into 5 quintiles.

\subsection{Ethical Considerations}

Ethical clearance was obtained from Hawassa University College of medicine and health science Institutional Review Board (IRB). Permission was obtained from South Omo Zone and Woreda health offices. Informed consent was obtained from the mother and father of study participating child. Data obtained from each study participant was kept confidential. 
Those children who are at risk and severely malnourished was referred to feeding programs available in the area and health facilities. Nutritional advice was also given for those mothers/caregivers on child feeding.

\section{Results}

Socio-demographic economic characteristics of the study participants

A total of 645 respondents of children aged 6-23 months participated in the study providing an overall response rate of $99.8 \%$. The mean $( \pm \mathrm{SD})$ family sizes of the households were $5.99 \pm 2.43$. The mean $( \pm \mathrm{SD})$ number of under five children per a household was $1.88 \pm 0.65$. Most of head of the households, $442(68.4 \%)$ were farmers by their occupation, whereas $101(15.6 \%) \quad$ were pastoralists, $86(13.3 \%) \quad$ were agro-pastoralists and the rest $14(2.2 \%)$ were employed. Of the total households, $135(20.9 \%)$ were found in the lowest/poorest wealth quintile (Table 1).

Table 1. Socio-demographic economic characteristics of the study participants $(n=645)$ in Benna Tsemay Woreda, South Omo Zone, Southern Ethiopia, 2016.

\begin{tabular}{lll}
\hline $\begin{array}{l}\text { Socio-demographic economic } \\
\text { variables }\end{array}$ & Frequency(n) & Percentage (\%) \\
\hline Total family size & & \\
2-3 individuals & 113 & 17.5 \\
$4-5$ individuals & 183 & 28.3 \\
$\geq 6$ individuals & 349 & 54.0 \\
Mean ( \pm SD) & $5.99 \pm 2.43$ & \\
Number of $<$ 5 children in the HH & & \\
1 & 172 & 26.6 \\
2 & 387 & 59.9 \\
3 & 77 & 11.9 \\
Mean ( \pm SD) & $1.88 \pm 0.65$ & \\
Father's education & & \\
No formal education & 552 & 85.4 \\
Primary education & 48 & 7.4 \\
Secondary education & 37 & 5.7 \\
Occupation of house hold head & & \\
Farmer & 372 & 57.7 \\
Pastoralist & 161 & 25.0 \\
Agro-pastoralist & 112 & 17.4 \\
Wealth index & & 20.9 \\
Lowest & 135 & 19.1 \\
Second & 121 & 20.5 \\
Middle & 132 & \\
Fourth & & \\
Richest & & \\
\hline & & \\
\hline
\end{tabular}

\section{Maternal characteristics}

The mean $( \pm \mathrm{SD})$ age of mothers/caregivers was $26.75 \pm 5.56$, ranged between 18 and 60 years. From the study participant, $252(39.0 \%)$ were tradition religion followers, $180(27.9 \%)$ had no religion, the rest 175 (27.1) were Protestant in religion. About $602(93.2 \%)$ of mothers of children were married. About 582 (90.1\%) mothers and 552 (85.4\%) fathers of the children had no formal education. About 473 (73.2\%) of the mothers were in a monogamous and $172(26.6 \%)$ were in polygamy type of marriage (Table 2).

Table 1. Maternal characteristics of the study participants, Benna Tsemay Woreda, South Omo Zone, Southern Ethiopia, 2016.

\begin{tabular}{|c|c|c|}
\hline Maternal characteristics & Frequency (n) & Percentage (\%) \\
\hline \multicolumn{3}{|l|}{ Maternal age (in years) } \\
\hline $15-19$ years & 22 & 3.4 \\
\hline $20-24$ years & 206 & 31.9 \\
\hline $25-29$ years & 264 & 40.9 \\
\hline$\geq 30$ years & 153 & 23.7 \\
\hline Mean $( \pm \mathrm{SD})$ & $26.75 \pm(5.56)$ & \\
\hline \multicolumn{3}{|l|}{ Religion of mothers } \\
\hline Orthodox & 36 & 5.6 \\
\hline Protestant & 175 & 27.1 \\
\hline Traditional & 252 & 39.0 \\
\hline No religion & 180 & 27.9 \\
\hline \multicolumn{3}{|l|}{ Marital status of mother } \\
\hline Married & 602 & 93.2 \\
\hline Divorced/separated & 24 & 3.7 \\
\hline Windowed & 19 & 2.9 \\
\hline \multicolumn{3}{|l|}{ Maternal education } \\
\hline No formal education & 582 & 90.1 \\
\hline Primary education & 40 & 6.2 \\
\hline Secondary education & 19 & 2.9 \\
\hline \multicolumn{3}{|l|}{ Maternal occupation } \\
\hline Housewives & 400 & 61.9 \\
\hline Livestock herding & 48 & 7.4 \\
\hline Farming & 185 & 28.6 \\
\hline \multicolumn{3}{|l|}{ Marriage type } \\
\hline Monogamous & 473 & 73.2 \\
\hline Polygamous & 172 & 26.6 \\
\hline \multicolumn{3}{|l|}{ Marriage order } \\
\hline $1^{\mathrm{st}}$ wives & 555 & 85.9 \\
\hline $2^{\text {nd }}$ wives & 85 & 13.2 \\
\hline \multicolumn{3}{|c|}{$\begin{array}{l}\text { Total number of children born to a } \\
\text { mother }\end{array}$} \\
\hline$\leq$ two children & 217 & 33.6 \\
\hline 3-6 children & 337 & 52.2 \\
\hline$\geq 7$ children & 91 & 14.1 \\
\hline $\operatorname{Mean}( \pm \mathrm{SD})$ & $3.87 \pm 2.20$ & \\
\hline \multicolumn{3}{|c|}{$\begin{array}{l}\text { Access to information on child } \\
\text { feeding }\end{array}$} \\
\hline Yes & 545 & 84.4 \\
\hline No & 100 & 15.5 \\
\hline
\end{tabular}

\section{Child's characteristics}

More than half, 361 (55.9\%) of the children were male and $284(44.0 \%)$ were female. The mean $( \pm \mathrm{SD})$ age of the children was $12.8 \pm 5.50$ with the minimum and maximum of 6 and 23 months, respectively. Most of the child birth order were $1^{\text {st }}$ born $115(17.8 \%), 2^{\text {nd }}$ born $104(16.1 \%), 3^{\text {rd }}$ born $85(13.2 \%)$ and $341(52.8 \%)$ of them were $4^{\text {th }}$ and above born. About 469 $(72.6 \%)$ of the mothers had a birth interval of less than 23 months, $176(27.2 \%)$ had a birth interval at least 23 months between the recent two births (Table 3).

Table 3. Child characteristics of the study participants, Benna Tsemay Woreda, South Omo Zone, Southern Ethiopia, 2016.

\begin{tabular}{lll}
\hline Child characteristics & Frequency (n) & Percentage (\%) \\
\hline Sex of children & & \\
Male & 361 & 55.9 \\
Female & 284 & 44.0 \\
Children's age (in month) & & \\
6-8 months & 178 & 27.6 \\
9-11 months & 121 & 18.7 \\
\hline
\end{tabular}




\begin{tabular}{lll}
\hline Child characteristics & Frequency $(\mathbf{n})$ & Percentage (\%) \\
\hline $12-23$ months & 346 & 53.6 \\
Mean $( \pm S D)$ & $12.8 \pm(5.50)$ & \\
$\begin{array}{l}\text { Birth order of the index child } \\
1^{\text {st }} \text { born }\end{array}$ & 115 & 17.8 \\
$2^{\text {nd }}$ born & 104 & 16.1 \\
$3^{\text {rd }}$ born & 85 & 13.2 \\
$\geq 4^{\text {th }}$ and above & 341 & 52.8 \\
Birth interval between the most & & \\
recent two births & & \\
$\leq 23$ months & 469 & 72.6 \\
$>23$ months & 176 & 27.2 \\
\hline
\end{tabular}

Water supply, sanitation and personal hygiene conditions

Among the respondents, 240 (37.2\%) of the households did not have toilet facility. On the other hand, $96(14.9 \%)$ of the households dispose their solid wastes in an open field. The main sources of drinking water for the households were from non-improved source accounted 617 (95.5\%) and improved source accounted 474 (73.3\%). About $343(53.2 \%)$ of the respondents did not treat water before drinking, posing a possible risk of water-borne diseases. This study has revealed that $415(64.2 \%)$ of the mothers practiced washing their hands before and after feeding their child (Table 4).

Table 4. Water supply, environmental and personal hygiene conditions of the study participants (n=645), Benna Tsemay Woreda, South Omo Zone, Southern Ethiopia, 2016.

\begin{tabular}{lll}
\hline Variable & $\begin{array}{l}\text { Frequency } \\
\text { (n) }\end{array}$ & $\begin{array}{l}\text { Percentage } \\
\text { (\%) }\end{array}$ \\
\hline Type of toilet/latrine facilities & & \\
No toilet facility/bush/open field & 240 & 37.2 \\
Traditional pit latrine without shade & 333 & 51.5 \\
Latrine covered with shade & 69 & 10.7 \\
Method of solid waste disposal & & \\
Dumped in street/open field disposal & 96 & 14.9 \\
Common pit & 66 & 10.2 \\
Buried/keeping in compound for fertilizer & 132 & 20.2 \\
Burning & 351 & 54.3 \\
Sources of drinking water & & \\
Improved source & 474 & 73.3 \\
Non improved source & 617 & 95.5 \\
Use of treated water & & \\
No & 343 & 53.2 \\
Yes & 302 & 46.8 \\
Time to fetch water in minutes & & \\
$<60$ minutes & 365 & 56.5 \\
$\geq 60$ minutes & 280 & 43.3 \\
Hand washing before and after feeding & & \\
child & & \\
Yes & 415 & 64.2 \\
No & 230 & 35.6 \\
\hline
\end{tabular}

About $461(71.5 \%)$ of them others reported that there are health extension services in their kebele. It was also identified that $184(28.5 \%)$ of the respondents did not visit a health extension service. About $536(83.0 \%)$ of children were vaccinated except $109(16.9 \%)$ who had never been vaccinated. About 223 (34.5\%) of children had history of illness within the past two weeks prior to the survey (Table 5).

Table 5. Health service availability and health seeking behavior of the study participants (n=645), Benna Tsemay woreda, South Omo Zone, Southern Ethiopia, 2016.

\begin{tabular}{lll}
\hline Variable & Frequency(n) & Percentage (\%) \\
\hline Availability of health extension & & \\
service in the kebeles & & \\
Yes & 461 & 71.5 \\
No & 184 & 28.5 \\
Child ever vaccinated & & \\
Yes & 536 & 83.0 \\
No & 109 & 16.9 \\
Type of vaccines taken & & \\
BCG & 427 & 66.1 \\
Polio & 532 & 82.4 \\
Pentavalent & 147 & 22.8 \\
DPT & 407 & 63.0 \\
Measles & 310 & 48.0 \\
Vitamin A supplementation & & \\
during the last 6 months & & \\
Yes & 218 & 33.7 \\
No & 427 & 66.1 \\
Child's sickness in the past 2 & & \\
weeks & & \\
Yes & 223 & 34.5 \\
No & 422 & 65.3 \\
Child taken to health institution & & \\
during sickness & & \\
Yes & 64 & \\
No & & \\
\hline
\end{tabular}

\section{Nutritional status of study participants}

The mean height $( \pm \mathrm{SD})$, weight $( \pm \mathrm{SD})$ and $\mathrm{MUAC}( \pm \mathrm{SD})$ of the study participants were $73.03 \mathrm{~cm}( \pm 6.13), 8.60 \mathrm{~kg}( \pm 1.51)$ and $13.24 \mathrm{~cm}( \pm 0.95)$, respectively.

Mean $z$ score values of pastoralist children

The mean LAZ, WLZ and WAZ scores were-1.14, -0.36 and -0.97 respectively. The mean LAZ, WLZ and WAZ scores were negative in all age groups. The mean LAZ increases with age.

Health service availability and health Seeking behavior

Table 6. Mean \pm SD of LAZ, WLZ and WAZ score of pastoralist children by age groups, Benna Tsemay woreda, South Omo Zone, Southern Ethiopia, 2016.

\begin{tabular}{lllll}
\hline \multirow{2}{*}{ Anthropometric measurements } & $\begin{array}{l}\mathbf{6 - 8} \text { months } \\
\mathbf{n}=\end{array}$ & $\begin{array}{l}\mathbf{9 - 1 1} \text { months } \\
\mathbf{n}=\end{array}$ & $\begin{array}{l}\mathbf{1 2 - 2 3} \text { months } \\
\mathbf{n =}\end{array}$ & $\begin{array}{l}\text { All children } \\
\mathbf{n}=\end{array}$ \\
\cline { 2 - 5 } & $\mathbf{M e a n} \pm \mathbf{S D}$ & Mean \pm SD & Mean \pm SD & Mean \pm SD \\
\hline Length-for-age z score & $-0.66 \pm 1.36$ & $-0.80 \pm 1.35$ & $-1.51 \pm 1.43$ & $-1.14 \pm 1.45$ \\
Weight-for-length z score & $-0.06 \pm 5.87$ & $-0.47 \pm 1.26$ & $-0.48 \pm 1.24$ & $-0.36 \pm 3.26$ \\
Weight-for-age z score & $-0.87 \pm 1.21$ & $-0.85 \pm 1.15$ & $-1.07 \pm 0.99$ & $-0.97 \pm 1.09$ \\
\hline
\end{tabular}


Prevalence of stunting, wasting and underweight of pastoralist children

Anthropometric measurements of weight and height of children were performed to identify the nutritional status. Accordingly, stunting was found to be a common nutritional problem, in which 177 (27.4\%) of children were found below
-2SD while $9.3 \%$ of children were severely stunted. Nighty nine $(15.3 \%)$ of children also were underweight while 64 $(9.9 \%)$ were wasted. The prevalence of stunting was higher for children of 12-23 month old compared to the other age groups. The prevalence of wasting was low for all age groups (Table 7).

Table 7. Prevalence of stunting, wasting and underweight of pastoralist children by age groups, Benna Tsemay Woreda, South Omo Zone, Southern Ethiopia, 2016.

\begin{tabular}{|c|c|c|c|c|}
\hline \multirow[t]{2}{*}{ Anthropometric measurements } & $\begin{array}{l}\text { 6-8 months } \\
n=\end{array}$ & $\begin{array}{l}\text { 9-11 months } \\
\mathrm{n}=\end{array}$ & $\begin{array}{l}\text { 12-23 months } \\
\mathrm{n}=\end{array}$ & $\begin{array}{l}\text { All children } \\
\mathrm{n}=\end{array}$ \\
\hline & n (\%) & n (\%) & n (\%) & n (\%) \\
\hline \multicolumn{5}{|l|}{ Stunting } \\
\hline Normal ( $\geq-2 S D)$ & $148(83.1)$ & $101(83.5)$ & $219(63.3)$ & $468(72.4)$ \\
\hline Stunted $(<-2 \mathrm{SD})$ & $30(16.9)$ & $20(16.5)$ & $127(36.7)$ & $177(27.4)$ \\
\hline \multicolumn{5}{|l|}{ Wasting } \\
\hline Normal ( $\geq-2 S D)$ & $161(90.4)$ & 111(91.7) & $309(89.3)$ & $581(90.1)$ \\
\hline Wasted (<-2SD) & $17(9.6)$ & $10(8.3)$ & $37(10.7)$ & $64(9.9)$ \\
\hline \multicolumn{5}{|l|}{ Underweight } \\
\hline Norma $1(\geq-2 S D)$ & $152(85.4)$ & $100(82.6)$ & $294(85.0)$ & $546(84.5)$ \\
\hline Underweight (<-2SD) & $26(14.6)$ & $21(17.4)$ & $52(15.0)$ & $99(15.3)$ \\
\hline
\end{tabular}

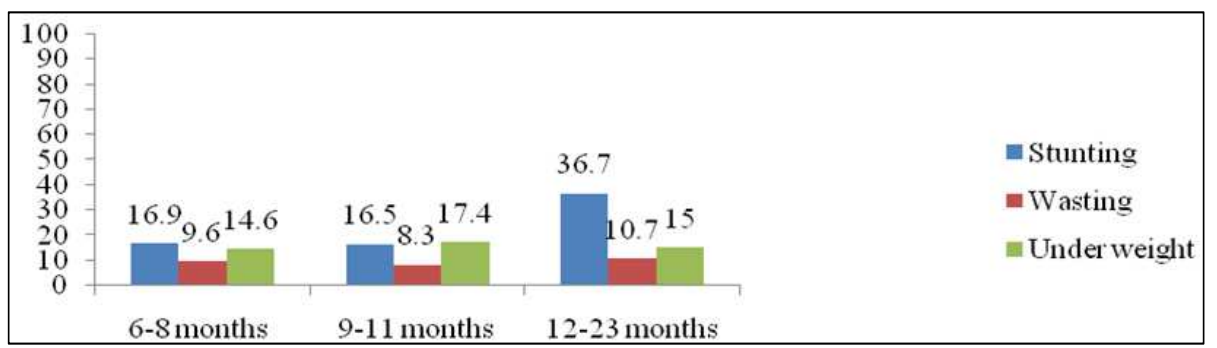

Figure 1. Nutritional status of pastoralist children aged 6-23 months in Benna Tsemay Woreda, South Omo Zone, Southern Ethiopia, 2016 (n=645).

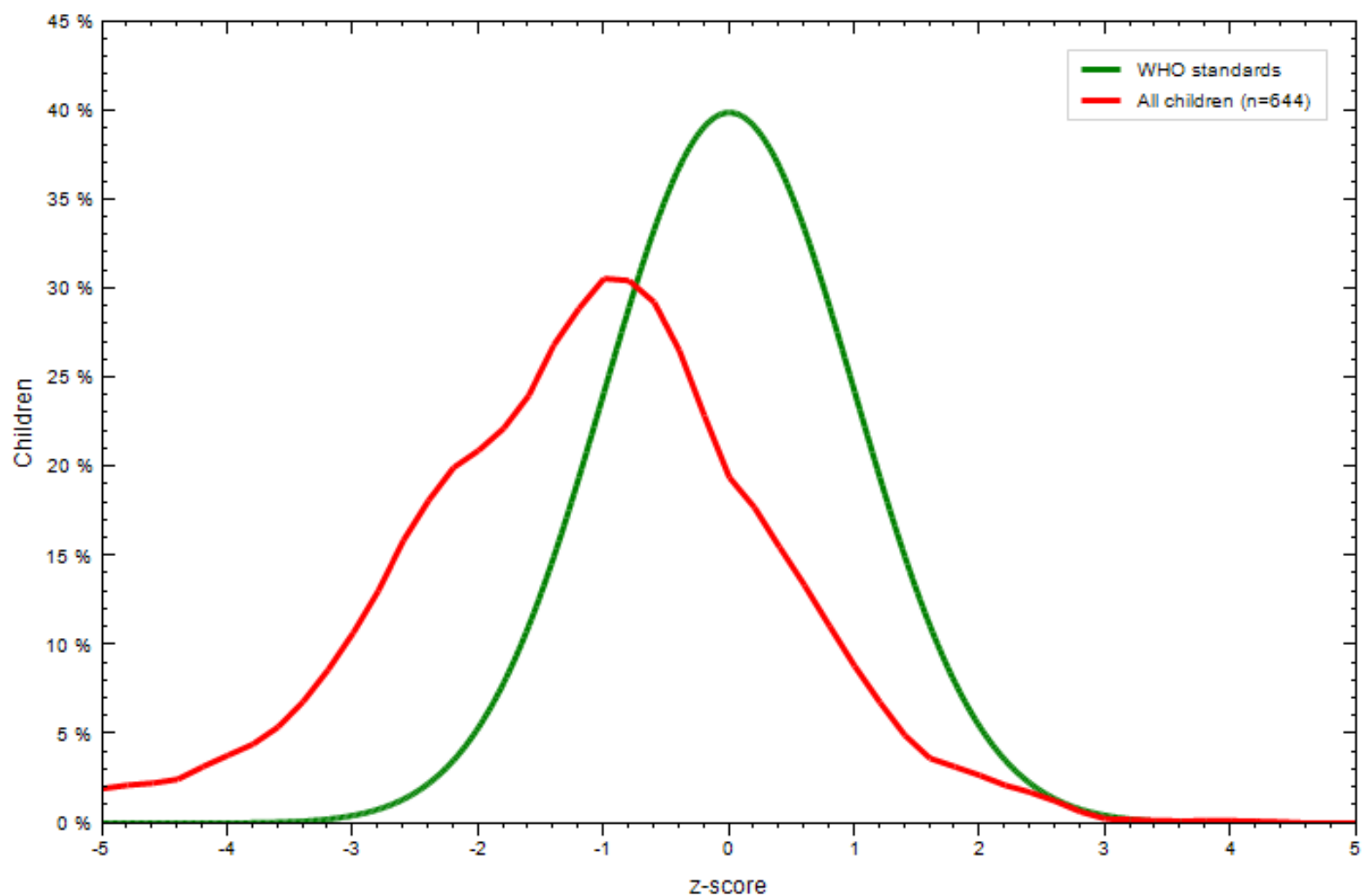

Figure 2. Distribution of stunting among children 6-23 months old pastoralist communities compared with WHOs standard population, Benna Tsemay Woreda, South Omo Zone, Southern Ethiopia, $2016(n=645)$. 


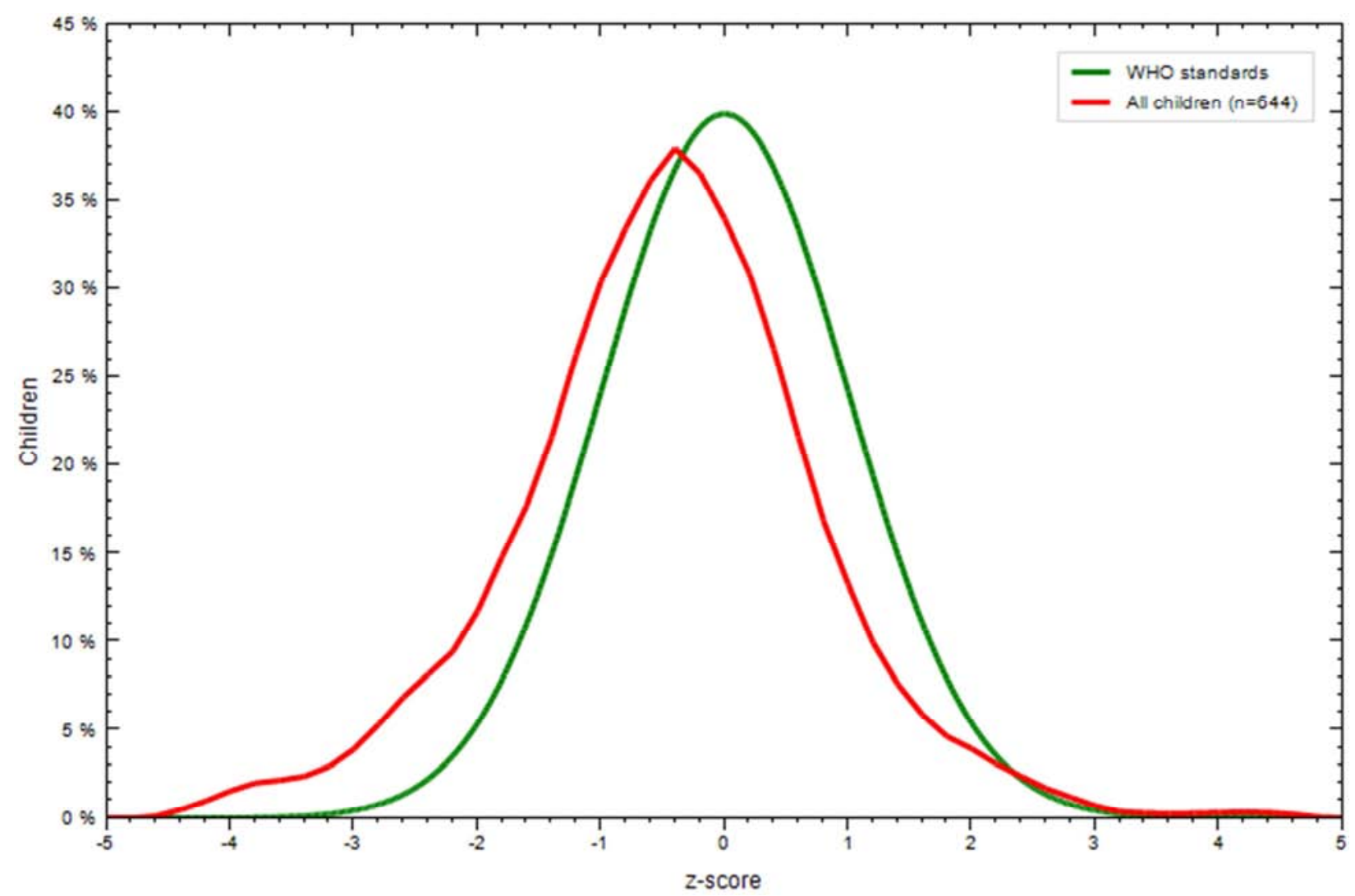

Figure 3. Distribution of wasting among children 6-23 months old in pastoralist communities, compared with WHOs standard population, Benna Tsemay Woreda, South Omo Zone, Southern Ethiopia, 2016 (n=645).

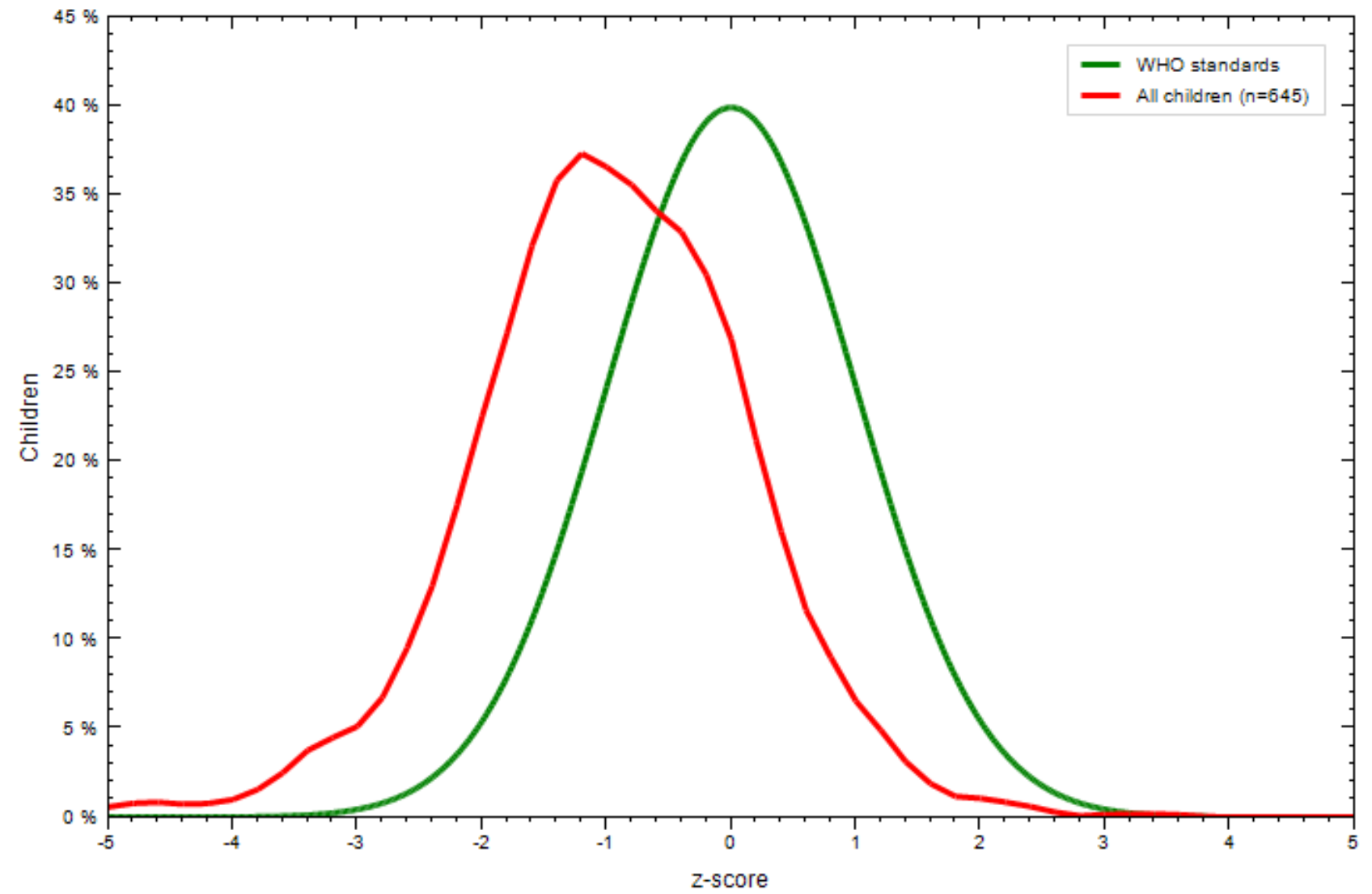

Figure 4. Distribution of underweight among children 6-23 months old in pastoralist communities compared with WHOs standard population, Benna Tsemay Woreda, South Omo Zone, Southern Ethiopia, 2016 (n=645). 
Factors associated with stunting among children in pastoralist communities

This study showed, being older child (12-23 months) $(\mathrm{AOR}=3.29,95 \% \mathrm{CI}, 2.03-5.32)$, being from agro-pastoralist (AOR $=0.46,95 \% \mathrm{CI}, 0.24-0.88)$, middle wealth quantile household $(\mathrm{AOR}=0.40,95 \% \mathrm{CI}, 0.20-0.77)$, use of treated water $(\mathrm{AOR}=0.60,95 \% \mathrm{CI}, 0.37-0.96)$, being second birth order $(\mathrm{AOR}=2.17,95 \% \mathrm{CI}, 1.11-4.24)$, being female child $(\mathrm{AOR}=0.55,95 \% \mathrm{CI}, 0.37-0.82)$ and good child feeding practice of mothers $(\mathrm{AOR}=0.47,95 \% \mathrm{CI}, 0.28-0.78)$ did show significant association with stunting $(\mathrm{p}<0.05)$ (Table 8$)$.

Out of the total stunted children, $127(36.7 \%)$ were in the age range of 12-23 months and children in this age group had 3.29 times higher risk of being stunted than children 6-8 months old $(\mathrm{AOR}=3.29,95 \% \mathrm{CI}, 2.03-5.32)$. Sex of the children is also significantly associated with stunting. Female children's were $45 \%$ less likely to be stunted than male children $(\mathrm{AOR}=0.55,95 \% \mathrm{CI}, 0.37-0.82)$. Birth order of the index child was significantly associated with stunting. A child who's born on second order of birth was 2.17 times more likely to be stunted as compared to those children born on the first order of birth $(\mathrm{AOR}=2.17,95 \% \mathrm{CI}, 1.11-4.24)$.

Children whose household heads are agro-pastoralist in their occupation were $54 \%$ less likely to be affected by stunting than those children's whose household head were farmers in their occupation ( $\mathrm{AOR}=0.46,95 \% \mathrm{CI}, 0.24-0.88$ ). Children whose households with the middle wealth quintile were $60 \%$ less likely to be affected by stunting than children whose households had lowest wealth quintile ( $\mathrm{AOR}=0.40$, $95 \%$ CI, 0.20-0.77). Use of treated water showed statistically significant association with stunting. Children whose households use treated water had $40 \%$ lower risk of being stunted than those whose households did not treat water $(\mathrm{AOR}=0.60,95 \% \mathrm{CI}, 0.37-0.96)$.

Good child feeding practice of mothers was stastically significant association with stunting. Children whose mothers had good child feeding practice were $53 \%$ less likely to be stunted compared to those children's whose mothers had poor child feeding practice $(\mathrm{AOR}=0.47,95 \% \mathrm{CI}, 0.28-0.78)$ (Table 8).

Table 8. Predictors of stunting among children aged 6-23 months in pastoralist communities, Benna Tsemay Woreda, South Omo Zone, Southern Ethiopia, 2016.

\begin{tabular}{|c|c|c|c|c|c|}
\hline Variable & Stunted n (\%) & Normal/Non stunted n (\%) & Crude OR (95\%CI) & Adjusted OR (95\%CI) & P-value \\
\hline \multicolumn{6}{|c|}{ Children's age(in months) } \\
\hline 6-8 months & $30(16.9)$ & $148(83.1)$ & 1 & 1 & \\
\hline 9-11 months & $20(16.5)$ & $101(83.5)$ & $0.97(0.52,1.81)$ & $0.99(0.51,1.89)$ & 0.978 \\
\hline $12-23$ months & $127(36.7)$ & $219(63.3)$ & $2.86(1.82,4.48)$ & $3.29(2.03,5.32)$ & $0.001 * *$ \\
\hline \multicolumn{6}{|c|}{ Occupation of household head } \\
\hline Farmer & $106(28.5)$ & $266(71.5)$ & 1 & 1 & \\
\hline Pastoralist & $49(30.4)$ & $112(69.6)$ & $1.09(0.73,1.64)$ & $0.87(0.51,1.48)$ & 0.622 \\
\hline Agro-pastoralist & $22(19.6)$ & $90(80.4)$ & $0.61(0.36,1.02)$ & $0.46(0.24,0.88)$ & $0.019 * *$ \\
\hline \multicolumn{6}{|l|}{ Wealth index } \\
\hline Lowest & $54(40.0)$ & $81(60.0)$ & 1 & 1 & \\
\hline Second & $35(28.9)$ & $86(71.1)$ & $0.61(0.36,1.02)$ & $0.53(0.29,0.97)$ & 0.042 \\
\hline Middle & $28(20.9)$ & $106(79.1)$ & $0.39(0.23,0.68)$ & $0.40(0.20,0.77)$ & $0.007 * *$ \\
\hline Fourth & $31(25.2)$ & $92(74.8)$ & $0.50(0.29,0.86)$ & $0.65(0.32,1.35)$ & 0.257 \\
\hline Richest & $29(22.0)$ & $103(78.0)$ & $0.42(0.24,0.72)$ & $0.54(0.26,1.15)$ & 0.114 \\
\hline \multicolumn{6}{|l|}{ Use of treated water } \\
\hline No & $105(30.6)$ & $238(69.4)$ & 1 & 1 & \\
\hline Yes & $72(23.8)$ & $230(76.2)$ & $0.71(0.50,1.00)$ & $0.60(0.37,0.96)$ & $0.035 * *$ \\
\hline \multicolumn{6}{|c|}{ Birth order of the index child } \\
\hline $1^{\text {st }}$ born & $30(26.1)$ & $85(73.9)$ & 1 & 1 & \\
\hline $2^{\text {nd }}$ born & $37(35.6)$ & $67(64.4)$ & $1.56(0.87,2.79)$ & $2.17(1.11,4.24)$ & $0.022 * *$ \\
\hline $3^{\text {rd }}$ born & $20(23.5)$ & $65(76.5)$ & $0.87(0.45,1.67)$ & $1.17(0.56,2.45)$ & 0.670 \\
\hline$\geq 4^{\text {th }}$ and above & $90(26.4)$ & $251(73.6)$ & $1.01(0.62,1.64)$ & $1.85(0.96,3.56)$ & 0.066 \\
\hline \multicolumn{6}{|l|}{ Sex of a child } \\
\hline Male & $114(31.6)$ & $247(68.4)$ & 1 & 1 & \\
\hline Female & $63(22.2)$ & $221(77.8)$ & $0.61(0.43,0.88)$ & $0.55(0.37,0.82)$ & $0.003 * *$ \\
\hline \multicolumn{6}{|c|}{ Child feeding practice of mothers } \\
\hline Poor practices $(<7.10)$ & $107(30.6)$ & $243(69.4)$ & 1 & 1 & \\
\hline Good practices $(\geq 7.10)$ & $43(18.4)$ & $191(81.6)$ & $0.51(0.34,0.76)$ & $0.47(0.28,0.78)$ & $0.004 * *$ \\
\hline
\end{tabular}

$1=$ Reference group

**Variables which shown significant association during the multivariate analysis at $\mathrm{p}$ value $<0.05$

Mother's age (in years), marriage type, maternal education, time to fetch water in minutes, access to information on child feeding, child feeding practice of mothers, minimum meal frequency didn't show significant association with stunting $(\mathrm{p}<0.05)$ and adjusted for those significant variables.

Marriage order, maternal education, fathers education, wealth index, use of treated water, birth order of the index child, birth interval between the recent two birth, child ever vaccinated, hand washing before and after feeding child, availability of health service and child feeding practice of mothers didn't show significant association with wasting $(p<0.05)$ and adjusted for significant variables.

Head of the household, mother's age (in years), marital status of mother, marriage type, fathers education, wealth 
index, total number of children born to a mother, birth order of the index child, birth interval between the recent two births, maternal occupation, child ever vaccinated, child ever taken to health institution, hand washing before and after feeding child, availability of health service, maternal knowledge, child feeding practice of mothers and minimum dietary diversity did show significant association with underweight $(\mathrm{p}<0.05)$ and adjusted for significant variables.

Factors associated with wasting among children in pastoralist communities

According to the multivariate analysis, having large family size ( $\geq 6$ individuals) ( $\mathrm{AOR}=30.93,95 \% \mathrm{CI}, 4.91-194.7)$, polygamous marriage $(\mathrm{AOR}=2.46,95 \% \mathrm{CI}, 1.07-5.61)$, being from agro-pastoralist $(\mathrm{AOR}=0.19,95 \% \mathrm{CI}, 0.05-0.66)$ and farming as maternal occupation $(\mathrm{AOR}=3.00,95 \% \mathrm{CI}$, 1.36-6.62) did show significant association with wasting $(\mathrm{p}<0.05)$.
In this study, having large family size was found to be a risk factor for wasting. Children living in households with greater than or equal to six family members were 30.93 times more likely get wasted than those children living in households with two to three family members ( $\mathrm{AOR}=30.93,95 \% \mathrm{CI}, 4.91-194.7)$.

Children whose mothers had in polygamy type of marriage was 2.46 times more likely to be wasted as compared to children whose mothers had in monogamy type of marriage (AOR=2.46, 95\%CI, 1.07-5.61).

Children whose household heads are agro-pastoralist in their occupation were $81 \%$ lower risk of being affected by wasting than those children's whose household head were farmers in their occupation ( $\mathrm{AOR}=0.19,95 \% \mathrm{CI}, 0.05-0.66$ ).

Children whose mothers are farmers in their occupation were 3 times more likely to be affected by wasting than those children's whose mothers were housewife in their occupation $(\mathrm{AOR}=3.00,95 \% \mathrm{CI}, 1.36-6.62)$ (Table 9).

Table 9. Predictors of wasting among children 6-23 months old in pastoralist communities, Benna Tsemay Woreda, South Omo Zone, Southern Ethiopia, 2016.

\begin{tabular}{|c|c|c|c|c|c|}
\hline Variable & Wasted & Normal weight/length & Crude OR (95\%CI) & Adjusted OR (95\%CI) & P-value \\
\hline \multicolumn{6}{|l|}{ Total family size } \\
\hline 2-3 individuals & $6(5.3)$ & $107(94.7)$ & 1 & 1 & \\
\hline 4-5 individuals & $21(11.5)$ & $162(88.5)$ & $2.31(0.90,5.91)$ & $8.51(1.49,48.69)$ & 0.016 \\
\hline$\geq 6$ individuals & $37(10.6)$ & $312(89.4)$ & $2.11(0.86,5.15)$ & $30.93(4.91,194.7)$ & $0.001 * *$ \\
\hline \multicolumn{6}{|l|}{ Marriage type } \\
\hline Monogamous & $41(8.7)$ & $432(91.3)$ & 1 & 1 & \\
\hline \multicolumn{6}{|c|}{ Occupation of household head } \\
\hline Farmer & $51(13.7)$ & $321(86.3)$ & 1 & 1 & \\
\hline Pastoralist & $8(5.0)$ & $153(95.0)$ & $0.32(0.15,0.71)$ & $0.35(0.13,0.93)$ & 0.035 \\
\hline Agro-pastoralist & $5(4.5)$ & $107(95.5)$ & $0.29(0.11,0.75)$ & $0.19(0.05,0.66)$ & $0.009 * *$ \\
\hline \multicolumn{6}{|c|}{ Maternal occupation } \\
\hline Housewives & $37(9.3)$ & $363(90.8)$ & 1 & 1 & \\
\hline
\end{tabular}

$1=$ Reference group

**Variables which shown significant association during the multivariate analysis at $\mathrm{p}$ value $<0.05$

\section{Factors associated with underweight among children in pastoralist communities}

The result of multivariate logistic regression analysis revealed that, being from pastoralist $(\mathrm{AOR}=3.18,95 \% \mathrm{CI}, 1.74-5.81)$ and being female child $(\mathrm{AOR}=0.35,95 \% \mathrm{CI}, 0.14-0.89)$ did show significant association with underweight $(\mathrm{p}<0.05)$.

Children whose household heads are pastoralist in their occupation were 3.18 times more likely to be affected by underweight than those children's whose household head were farmers in their occupation ( $\mathrm{AOR}=3.18,95 \% \mathrm{CI}, 1.74-5.81$ ).

Sex of the child is also found significantly associated with underweight; female children were about $65 \%$ lower risk of being underweight as compared to male children ( $\mathrm{AOR}=0.35,95 \% \mathrm{CI}, 0.14-0.89)$ (Table 10).

Table 10. Predictors of underweight among children 6-23 months old in pastoralist communities, Benna Tsemay Woreda, South Omo Zone, Southern Ethiopia, 2016.

\begin{tabular}{|c|c|c|c|c|c|}
\hline Variable & Underweight & Normal weight/age & Crude OR (95\%CI) & Adjusted OR (95\%CI) & P-value \\
\hline \multicolumn{6}{|c|}{ Occupation of household head } \\
\hline Farmer & 41(11.0) & $331(89.0)$ & 1 & 1 & \\
\hline Pastoralist & $50(31.1)$ & 111(68.9) & $3.63(2.28,5.79)$ & $3.18(1.74,5.81)$ & $0.001 * *$ \\
\hline Agro-pastoralist & $8(7.1)$ & 104(92.9) & $0.62(0.28,1.36)$ & $0.61(0.25,1.50)$ & 0.289 \\
\hline \multicolumn{6}{|l|}{ Sex of a child } \\
\hline Male & $67(18.6)$ & 294(81.4) & 1 & 1 & \\
\hline
\end{tabular}

$1=$ Reference group

** Variables which shown significant association during the multivariate analysis at $\mathrm{p}$ value $<0.05$ 


\section{Discussion}

According to this study, the prevalence of stunting, wasting and underweight was $27.40 \%, 9.90 \%$ and $15.3 \%$, respectively. The finding was similar with the report of EDHS 2014, which reported a prevalence of $23.2 \%, 16.6 \%$ and $12.5 \%$ of children less than two year were stunted, wasted, and underweight, respectively [10]. The prevalence of stunting and wasting among pastoralist children aged 6-23 months in Benna Tsemay woreda were similar to the finding of a study in Kenya, $28.19 \%$ and $8.8 \%$, respectively [3]. This study was consistent with a study conducted in Somali Region, Ethiopia which showed $17.5 \%, 22.9 \%$ and $19.5 \%$ of infants and young children were wasted, stunted and underweight respectively [38]. This study was also consistent with a study conducted in northern Ghana which showed the levels of stunting, underweight and wasting in these children were $27.2 \%, 17.6 \%$ and $8.2 \%$, respectively [17]. Based on the findings of this study, high prevalence of stunting was reported in the study area even if the prevalence of wasting and underweight were relatively lower. This could be due to the fact that, this community are minor and less privileged groups which may results to poor socio economic characteristics, poor health service delivery and lower literacy. This might be also be due to the difference in feeding frequency, food security at household level, lack of knowledge of the caregivers to provide balanced diet to their children and time variation. This might be due to differences in agro-ecology, feeding habits, lifestyles and demography between the two study areas.

Out of the total stunted children, $127(36.7 \%)$ were in the age range of 12-23 months and children in this age group had 3.29 times higher risk of being stunted than children 6-8 months old. As the age of children increased the prevalence of stunting also increased. This study was similar with the report of EDHS 2014, showed that the prevalence of stunting increases as the age of a child increase; with the highest prevalence of chronic malnutrition found in children age 12-23 months (52\%) and lowest in children between ages 6-8 months (9\%) [10]. This study was also consistent with the study conducted in Lalibela Town Administration, showed that children aged 11-23 months were 2.3 times more likely to be affected by stunting compared to children age 6-8 months [37]. This finding was also consistent with the study in Vietnam which reported the highest risk of stunting among children aged 12-23 months and children in the youngest age group, (6-11 months) had a significantly lower risk of being stunting than children in the older age groups [26]. In Democratic Republic of Congo, an inverse linear association between age and stunting among children was reported [21].

The probable reason for higher prevalence of stunting among 12-23 months old children might be attributed to decreasing breast feeding frequency as children age get older so the energy required for their age might decrease due to low consumption of breast milk. The other possible reason could be that caring practices usually tend to decrease when children grown-up than infants and also usually when children get older they shift to eat and share family foods. The other possible justification for this difference may be explained by the fact that foods for weaning are typically introduced to children in the older age group, thus increasing their exposure to infections and susceptibility to illness. This tendency, coupled with inappropriate or inadequate feeding practices, may contribute to faltering nutritional status among children in these age groups [10].

Sex of the children is also significantly associated with stunting. Female children's were $45 \%$ lower risk of being stunted than male children. This finding was consistent with the study conducted in Lalibela Town Administration, showed that female children were about $25 \%$ lower risk of being stunted as compared to male children [37]. This finding is also similar with the study conducted in West Gojam Zone, Bule Hora district and Pastoral Community of Dollo Ado District, Somali Region, showed that male children were more likely to be stunted as compared to female children [6, 4, 31], respectively. Similarly, many studies in Ethiopia and elsewhere have reported that under-five male children are more likely to become stunted than their female counterparts $[33,13,19,28,12]$.

On the contrary, the study conducted in Amita Pradhana, showed that female children are more likely to be stunted as compared to male but the association was significant only in case of moderate stunting [18]. This could be because boys are more influenced by environmental stress than girls. Thus, boys are more likely to display impact of chronic under nutrition; especially in environments where stresses are at play, like repeated infections and exposure to toxins and air pollutants $[19,28]$.

Birth order of the index child was significantly associated with stunting. A child who's born on second order of birth was 2.17 times more likely to be stunted as compared to those children born on the first order of birth. This finding was in line with the study conducted in Mizan-Aman Town, Bench Maji Zone and Hossana Town, Southern Ethiopia, showed that children of 4 and above birth order were 2.3 times more likely to be stunted than children of first birth order [15, 25]. Similarly, a study conducted in Ibadan, Nigeria, showed that the child being the fourth or higher birth order 4.5 times more likely to be undernourished [14]. Similar finding was also observed in study conducted in agro-pastoral households in Afar Regional State of Ethiopia, revealed that children of first birth order are expected to beat a significantly higher risk of stunting than children of higher birth. This finding was also supported by EDHS 2011 [9]. This might be due to the fact that the family is unable to satisfy child dietary and other health care related services because of more number of children and might also be due to low awareness of family planning. This might be because of the mothers' tendency to shift to the new born child expecting more care is required forit [16].

Children whose household heads are agro-pastoralist in their occupation were $54 \%$ less likely to be affected by stunting than those children's whose household head were farmers in their occupation. The national nutrition baseline 
survey also indicated that the main occupation among the rural areas remains farming/ agriculture (86\%) [2]. This indicates that children from farmer fathers were more affected by acute malnutrition compared to government employee.

Children (age 6-23 months) from households in the middle wealth quintile were $60 \%$ less likely to be stunted than children whose households were in the lowest wealth quintile. The odds of being stunting also declined as wealth quintile increased from lowest to richest. This finding was similar to EDHS 2011, showed that higher proportion of children in the lowest household wealth quintile were stunted (49\%) than children in the highest wealth quintile (30\%). A similar inverse relationship was observed between households wealth and stunting levels of children [10]. This finding was in agreement with the study conducted in Lalibela Town Administration, showed that children age 6-59 months whose family had middle wealth quintile were about $47 \%$ times less likely to be affected by stunting than children whose family had lowest wealth quintile [37].

This might be due to children from greater income /rich families can have improved nutritional status. Rich families can afford more nutritious food, clean water, hygiene, and health care. This allows them to have a more diversified diet and to attain more effective child care activities. At the community level, greater income means better access to quality health care, improved water, and sanitation systems and greater access to information.

The finding of this study, showed that about 617 (95.5\%) of the households in the study population relied on unsafe water supply from unprotected water sources. Rural households are not use anappropriate treatment method to ensure that water is safe for drinking as compared to urban [9]. Therefore, diarrhea and water born diseases caused by unsafe drinking water at households' level might be increase the prevalence of malnutrition directly or indirectly. Present finding revealed that, method of water treatment showed statistically significant association withs tunting. Children whose households use treated water had $46 \%$ lower risk of being stunted than those whose households did not treat water. This finding was consistent with the study conducted in Nghean; where approximately $23 \%$ of households did not use a method of treating drinking water was more likely exposed to stunting [27]. On the contrary, the study conducted in Mbeere South Sub Country, Kenya, showed that there was no direct relationship between water treatment, use of source of drinking water and nutritional status $(p>0.05)$ [29].

In this study, having large family size was found to be a risk factor for wasting. Children living in households with greater than or equal to six family members were 30.93 times more likely get wasted than those children living in households with two to three family members. This was consistent with a study done in Dale Woreda, southern Ethiopia, which showed having a large family size was identified as major risk factors for wasting [23]. This was also in agreement with a study done in North West Ethiopia [24]. Similarly, a study reported by Babar and his colleagues showed that the larger the size of family the poorer the nutritional status of the children would be [5]. This could be partially explained in that, as the family members increase, there will be sharing of resources in household including food which will result in lack of adequate food especially for children [32]. Families with more children generally devote less time to take care of their children [16].

Children whose mothers had in polygamy type of marriage were 2.46 times more likely to be wasted as compared to children whose mothers had in monogamy type of marriage. Similarly, a study conducted in northern Tanzania, showed that polygamous households in a village becomes positively associated with child WHZ [11]. Another study conducted in Ibadan, Nigeria, showed that polygamous marriage was one of the maternal factors associated with under nutrition [14].

Children whose household heads are agro-pastoralist in their occupation were $81 \%$ lower risk of being affected by wasting than those children's whose household head were farmers in their occupation. Children whose mothers are farmers in their occupation were 3 times more likely to be affected by wasting than those children's whose mothers were house wife in their occupation.

Children whose household heads are pastoralist in their occupation were 3.18 times more likely to be affected by underweight than those children's whose household head were farmers in their occupation. This was consistent with a study done in agro-pastoral households in Afar Regional State of Ethiopia, revealed that children living in households having less experience in agro-pastoral mode of life were more vulnerable to malnutrition [16].

Sex of the child is also found significantly associated with underweight; female children were about $65 \%$ lower risk of being underweight as compared to male children. This finding was consistent with a study conducted in Bule Hora District, South Ethiopia, showed that male children were 2.5 times more likely to be under weight than female children [4]. This finding was also similar to a study conducted in Pastoral Community of Dollo Ado District, Somali Region, showed that male children were 1.7 times higher risk of being under-weighted as compared to female children [31]. This finding is also similarity with a number of other studies conducted in Kwara State, Nigeria, [30] and in Eastern Uganda [20] that found out male children is more likely to be underweight than females children's. This finding contradicts to a case study conducted in Garissa sub-county, showed that female children were significantly about 2 fold more likely to be underweight than male children [1]. Studies done in Ethiopia and Vietnam also reported that boys were more likely to be under-weight [19, 22].

Program managers, policy makers and local administrators should pay attention to improve the mother's knowledge towards child feeding practices, cultural food tabos, and dietary diversity for better child nutritional status.

Strengths of the study

Among the notable strengths of this study, it is the first study done in this thematic group of Benna and Tsemay children which gives important baseline information regarding nutritional status of children in pastoralist communities to all concerned partners. This study is community based on showing real nutritional condition of children 6-23 months of 
age. The study included large sample size in order to enhance the power of the findings. Incorporation of both quantitative and qualitative study designs could be considered as the strength. The study used both anthropometric measurement and dietary assessment to assess the nutritional status of pastoralist children in the study area. In this study also used wealth index to assess socio economic status of household since under estimation and over estimation of monthly income. In addition, logistic regression was also used in the statistical analysis, so the interaction was analyzed and confounding factors were controlled, also the most important factors were identified.

Limitations of the study

The cross sectional study design may not enable to determine causal relationships. There may be recall bias in 24 hour recall dietary assessment.

\section{Conclusions}

In conclusion, high numbers of pastoralist children are suffering from chronic malnutrition with low DDS. Large numbers of mothers have inadequate knowledge about IYCF practices. Poor child feeding practices were suboptimal among mothers and significantly associated with child nutritional status in the study area. Poor child feeding practices well predicted stunting among children in the study area.

Majority of mothers had a positive attitude about breast feeding initiation, provision of colostrum's for newborn infants and exclusive breastfeeding in the first six months among children's aged 6-23 months old in the community. But certain mothers had negative attitude about introduction of complementary feeding and dietary diversity which had an effect on the nutritional status among children's aged 6-23 months old in the community.

Among the nutritional problem identified, stunting was found to be the commonest one. Based on the findings of this study, high prevalence of stunting was reported in the study area even if the prevalence of wasting and underweight were relatively lower. The prevalence of stunting increased with age in which young children in age 12-23 months were more exposed to stunting.

Findings from this study showed that the predictors of stunting were being older child (12-23 months), being from agro-pastoralist, middle wealth quantile household, use of treated water, being second birth order, being female child and adequate maternal knowledge about appropriate child feeding. Being from pastoralist and being female child are the independent predictors of underweight. Whereas, having large family size, polygamous marriage, being from agro-pastoralist and farming as maternal occupation independently predicted wasting in the study area.

\section{Recommendations}

The following recommendations are suggested based on the results of this study: Provide sustained nutrition education programs to mothers focusing on appropriate feeding practice through community-based nutrition programs is critical to accelerate improvement in children nutritional status in the study area. Nutrition programs should also pay attention to cultural beliefs and food taboos on infant and young child feeding. Households should treat drinking water which is obtained from unprotected water sources and river by boiling, bleaching and strained through cloth. Use of family planning should be encouraged to help the family to have small family size which can improve household income and proper sharing of resources. There is a need to address the issues of polygamous marriage through multidisciplinary approach at community level should be carried out to consequently reduce wasting among children. Close monitoring of the gap between poorest, middle, and richest households can help in the reduction of the gap in nutritional status between children in the highest and lowest socio economic quintiles. The findings of this study had its implications for health care workers and other concerned bodies including policy makers to carry out the national nutrition strategy on IYCF by considering the living conditions of the pastoralist communities. Further longitudinal studies should be done to see unexplored variables (Antenatal care, seasonal factors, household food security and dietary adequacy of pastoralist children in the community) that were not included in this study.

\section{References}

[1] Abdulrahim M, Karama M, Makokha A (2015). Prevalence of underweight and its determinant factors among children aged 0-59 months: A case of Garissa sub-county. Int $J$ Health Sci, 5(9): 445-457.

[2] Addis Continental Institute of Public Health (2009). Community-Based Sub-Component of Ethiopian National Nutrition Program Baseline Survey Report.

[3] Amelia R, Masumi M and Mark M (2016). Stunting and wasting in children under two years old in a semi-nomadic pastoralist population in Kenya.

[4] Asfaw M, Mekitie W, Mohammed T, Lemessa D (2015). Prevalence of undernutrition and associated factors among children aged between six to fifty nine months in Blue Hora district, South Ethiopia. BMC Public Health 15:41.

[5] Babar N, Muzaffar R, Khan M, Imdad S (2010). Impact of socio economic factors on nutritional status in primary school children in Lahore. Pakistan J Ayub Abbottabad; 22 (4):15-8.

[6] Beka T, Wambui K, Zewditu G, Girum T (2009). Magnitude and determinants of stunting in children under five years of age in food surplus region of Ethiopia: The case of West Gojam Zone. Ethiop. J. Health Development 23:98-106.

[7] Black R, Victora C, Walker S, Zq B, Christian P, de Onis M, (2013). Maternal and child undernutrition and overweight in low-income and middle income countries. Lancet. 382:427-51.

[8] Central Statistical Agency (CSA) [Ethiopia]. The 2007 population and Housing Census of Ethiopia. Statistical Summary Report at National Level, Addis Ababa, Ethiopia.

[9] CSAE, International I. Ethiopia Demographic and Health Survey 2011. Addis Ababa, Ethiopia and Calverton, Maryland, USA: 2012. Federal Democratic Republic of Ethiopia Ministry of Health. Complimentary feeding practices for children aged 6 upto 24 months. Addis Ababa, Ethiopia, 2012. 
[10] Central Statistical Agency [Ethiopia] and ORC Macro (2014). Ethiopia Mini Demographic and Health Survey (EDHS) 2014. Addis Ababa, Ethiopia and Calverton, Maryland, USA.

[11] David W, Lawsona L, Susan J, Esther N, Bernard N, and Monique B, (2015). No evidence that polygamous marriage is a harmful cultural practice in northern Tanzania.

[12] Demissie S, Worku A (2013). Magnitude and Factors Associated with Malnutrition in Children 6-59 Months of Age in Pastoral Community of Dollo Ado District, Somali Region, Ethiopia. Sci J Public Health, 1(4):175-83.

[13] Deribew A, Alemseged F, Tessema F, Sena L, Birhanu Z, Sudhakar M, et al. Biadgilign (2010): malaria and under-nutrition: a community based study among under-five children at risk of malaria, south-west Ethiopia. PLoSOne, 5(5):e10775.

[14] Eme O, Oluwadolapo O, Adeyimika D (2014). Family and socio economic risk factors for under nutrition among children aged 6 to 23 Months in Ibadan, Nigeria. Pan African Medical Journal-ISSN: 1937-8688.

[15] Ermias A (2015). A thesis on the prevalence of stunting and associated factors among children age 6-59 months at Mizan-Aman Town, Bench Maji Zone, SNNPR Region, Ethiopia.

[16] Fentaw R, Bogale A, Abebaw D (2013). Prevalence of child malnutritionin agro-pastoral households in Afar Regional State of Ethiopia. Nutr Res Pract. 7 (2):122-31.

[17] Glover-A, Isaac A, Lynda L, Frank P, Gladys G, Asamoah L and Irmgard H (2016). Nutritional status of children 0-59 months in selected intervention communities in northern Ghana from the Africa RISING project in 2012; Archives of Public Health, 74:12.

[18] Gobotswang K (2008). Factors associated with nutritional status of the under five children Amita Pradhana. Asian journal of medical sciences.

[19] Hien N, Hoa N (2009). Nutritional status and determinants of malnutrition in children under three years of Age in Nghean. Vietnam Pak J Nutr; 8(7):958-64.

[20] Ingunn M, Stadskleiv E, Thorkild T, Henry W, Charles K, and James K (2008). Determinants of infant growth in Eastern Uganda: a community-based cross-sectional study: $B M C$ Public Health, 8:418.

[21] Kandala N, Madungu T, Emina J, Nzita K, Cappuccio F (2011). Malnutrition among children under the age of five in the Democratic Republic of Congo (DRC): does geographic location matter? BMC Public Health 11:261.

[22] Medhin G, Hanlon C, Dewey M, Alem A, Tesfaye F, Worku B (2010). Prevalence and predictors of undernutrition among infants aged six and twelve months in Butajira, Ethiopia: the P-Ma Mi E birth cohort. BMC Public Health; 10:27.

[23] Mekides W, Yifru B and Alemzewed C (2015). Determinants of underweight, stunting and wasting among school children BMC Public Health 15:8 DOI10.1186/s12889-014-1337-2.

[24] Mekonnen H, Tadesse T, Kisi T (2013). Malnutrition and its Correlates among Rural Primary school children of Fogera District, North west Ethiopia. Nutr Disorders Ther. S12:002. doi:10.4172/2161-0509.S12-002.
[25] Moges B, Feleke A, Meseret S, Doyore F (2015). Magnitude of Stunting and Associated Factors Among 6-59 Months Old Children in Hossana Town, Southern Ethiopia. J Clinic Res Bio eth 6:207.

[26] Nakamori M, Nguyen XN, Nguyen CK, Cao TH, Nguyen AT (2010). Nutritional status, feeding practice and incidence of infectious diseases among children aged 6 to 18 months in northern mountainous Vietnam. $J$ Med Invest 57:45-53.

[27] Nguyen NH, Nguyen NH (2009). Nutritional Status and Determinants of Malnutrition in Children Under Three Years of Age in Nghean, Vietnam Pakistan Journal of Nutrition 8:958-964.

[28] Olack B, Burke H, Cosmas L, Bamrah S, Dooling K, Feikin D (2011). Nutritional status of under-five children living in an informal urban settlement in Nairobi, Kenya. J Health Popul Nutr; 29(4):357-63.

[29] Qabale D (2014). Master thesis on nutritional status of children under five years, and assocoiated factors, in mbeere south sub country, Kenya.

[30] Raphael O, Funke I, Segun B, Foluke E (2011). Prevalence and Determinants of Malnutrition among Under-five Children of Farming Households in Kwara State, Nigeria: Canadian Center of Science and Education, Journal of Agricultural Science; $3(3)$.

[31] Solomon D, Amare W (2013). Magnitude and Factors Associated with Malnutrition in Children 6-59 Months of Age in Pastoral Community of Dollo Ado District, Somali Region, Ethiopia. Science Journal of Public Health. Vol. 1, No. 4, pp. 175-183.

[32] Teklebrhan T (2012). Predictors of Nutritional Status of Children Visiting Health Facilities in Jimma Zone, South West Ethiopia. International Journal of Advanced Nursing Science and Practice. 1-11.

[33] Teshome B, Kogi-Makau W, Getahun Z, Taye G (2009). Magnitude and determinants of stunting in children under five years of age in food surplus region of Ethiopia: The case of west gojam zone. Ethiop J Health Dev; 23(2):99-106.

[34] WHO (World Health Organization). Multicentre growth reference study group. WHO child growth standards: length/height-for-age, weight-for-length, weight-for-height and body mass index-for-age: methods and development. Geneva, Switzerland: WHO; 2006.

[35] WHO, UICEF, UCDavis, USAID, FANTA (2007). Indicators for assessing infant and young child feeding practices, part 1 definition: conclusions of a consensus meeting held 6-8 November in Washington D. C., USA.

[36] WHO and UNICEF (2009). Breastfeeding promotion and support in a baby friendly hospital. Geneva.

[37] Yalew B (2014). Prevalence of Malnutrition and Associated Factors among Children Age 6-59 Months at Lalibela Town Administration, North Wollo Zone, Anrs, Northern Ethiopia. $J$ Nutr Disorders Ther 4:132. doi:10.4172/2161-0509.1000132.

[38] Yirgu F, Addisalem M, Demewoz H and Barbara J. S (2015). Factors associated with nutritional status of infants and young children in Somali Region, Ethiopia: across-sectional study. BMC Public Health 15:846 DOI10.1186/s12889-015-2190-7. 